\title{
TIBF EXCHANGE RATE VOLATILITY AND PURCHASING POWER PARITY: DOES EURO MAKE ANY DIFFERENCE?
}

\author{
Meher Manzur and Felix Chan \\ Curtin University of Technology, Australia
}

\begin{abstract}
This paper provides a new test of the purchasing power parity (PPP) and its relevance for the Euro. Principal component analysis (PCA) is employed to construct a pooled measure of inflation for 12 Euro-currency countries. This measure is used to test the PPP for Euro against three major currencies, namely, those of the Japan, UK and USA. The test results are then used to measure the speed of adjustment of the deviations from parity using rolling and recursive regressions procedures. Finally, the forecasting accuracy of the PPP-based Euro exchange rates is compared with those given by the random walk model, and the synthetic Euro series provided by the European Central Bank. In general, the results are supportive of PPP.
\end{abstract}

Keywords: Purchasing power parity, Principal component analysis, Pooled inflation, Random walk.

JEL Classification: F31, G15.

\section{Introduction}

Exchange rates have been notoriously volatile since the switch to floating by the major currencies in the early 1970s (Manzur, 2003). Over the recent decades, many countries adopted a number of different approaches to manage exchange rates. The best example comes from Europe: 15 European Union member countries have now abandoned their national currencies and adopted a single currency (Euro). A number of emerging economies are at odds with variants of managed exchange rate regimes. Smaller countries like Panama and Ecuador have gone for dollarisation, and several other high inflation-countries like Zimbabwe, Mexico and Argentina are viewed as suspects to this extreme option. Thus, exchange rate volatility dominates policy debate and multinational business finance. 
Dornbusch's (1976) 'overshooting' model was among the first to provide useful insights to explain exchange rate volatility. This model views goods prices and wages as 'sticky' and slow to adjust, while asset market clears instantaneously. Consequently, the domestic monetary policy becomes impotent, rendering exchange rates to absorb shocks. This idea makes sense in theory; unfortunately, formal empirical tests do not provide evidence to support this hypothesis (Rogoff, 2002). The influential 'productivity bias' hypothesis, proposed by Balassa (1964) and Samuelson (1964), predicts that the currencies of more affluent countries are systematically overvalued due to higher relative prices of non-traded goods in those countries. However, further research has raised issues with the validity of Balassa-Samuelson thesis (Bahmani-Oskooee and Nasir, 2005). Despite Meese and Rogoff's (1983) influential result that the random walk model performs at least as well as structural and time series (both univariate and multivariate) models of exchange rates, the idea of 'disconnect' between exchange rates and the real economy has been subjected to a growing scepticism (Devereux and Engel, 2002).

Fortunately, the conclusions concerning the validity of purchasing power parity (PPP) are becoming increasingly reliable. This theory states that prices should be internationally arbitraged so that they are the same in all locations when expressed in a common currency (absolute PPP). A less strict version of this theory states that the change in the exchange rate is equal to the inflation differential (relative PPP). Historically, PPP has been the fulcrum in the study of exchange rate volatility. Its relevance has increased significantly, following the introduction of Euro in Europe. PPP has profound implications for several issues surrounding the Euro. It was argued that the nominal exchange rate volatility has now disappeared for the Euro zone, but the difference in the underlying inflation across countries and other cross-country differences may imply significant shocks to real exchange rates affecting trade flows, price level convergence, asset pricing and portfolio management (Koedijk, Ben and Mathijs 2004). Interest is also mounting in investigating if the economic integration through adoption of a single currency has accelerated the convergence towards PPP in the Euro zone.

This paper provides a new test of PPP and its relevance for the Euro. We introduced the method of principal component analysis (PCA) to construct a pooled measure of inflation among the 12 Euro countries. Given the overall inflation of the 12 Euro countries is not observable, a PCA on the inflation of 12 Euro countries is expected to provide a consistent measure of pooled inflation for the Euro zone. ${ }^{1}$ This measure of inflation is used to test the PPP condition for

\footnotetext{
${ }^{1}$ A related approach is the Factor Analysis (FA), which decomposes the observed data into a set of unobserved latent factors with different factor loadings, that is, the observed data is expressed as a (linear) combination of unobserved latent factors, whereas PCA computes the appropriate linear combination of the observed data to generate the unobserved variable. Since we intend to generate the unobserved measure of pooled inflation based on a linear combination of the observed inflation rates from the 12 countries, PCA is a more appropriate method.
} 
the Euro against the currencies of USA, UK and Japan. The test results are then used to measure the speed of adjustment of the deviations from PPP using rolling and recursive regressions procedures. Finally, the accuracy of the PCA-based PPP-euro exchange rates is compared with those given by simple forecasting rules such as no-change extrapolation, and the synthetic Euro series provided by the European Central Bank. In general, the results are supportive of PPP.

The paper makes several contributions. Firstly, as just mentioned above, the test of PPP for euro has useful policy and business implications. Secondly, most, if not all, PPP studies used quarterly or annual data. This paper used monthly observations, thereby adding a new dimension to the literature. Thirdly, our approach is simple, but innovative. While the method of PCA is widely used for constructing unobserved latent factors in many areas, especially in medical research, marketing, psychology and panel data econometrics, its application is relatively new in macroeconomics and international finance. Similarly, measuring the speed of convergence toward PPP using rolling and recursive regressions procedures is insightful. Finally, our approach enables us to provide a test for the predictive power of PPP. The results indicated that PPP tends to outperform the random walk model - a result that will probably be influential in understanding modern exchange rate dynamics.

The paper is organised as follows. A brief digression on the speed of adjustment of PPP deviations is given in the next section. Section 3 introduces the concept of PCA and the construction of the pooled inflation measure. Section 4 describes the data and preliminary analysis, followed by the empirical results in Sections 5 and 6. The last section concludes the paper.

\section{The Speed of Adjustment for PPP: A Digression}

PPP is perhaps the oldest and most controversial theory of exchange rate determination. It is also one of the most-heavily researched topics in international finance (Lan, 2003). Manzur (1990) was among the first to provide evidence to indicate that PPP is a long-run phenomenon. He was also among the first to provide a measure of the long run: his results identified five years as being a broad measure of the length of the long run in so far as PPP is concerned. There is now a consensus in the literature that PPP is a long-run phenomenon, but the issue of speed of convergence toward long-run PPP is puzzling.

Several approaches have been adopted to explore the notion of PPP deviations and their speed of adjustment to the long run. A measure of persistence is what is now known in the literature as the half-life of PPP deviations, based on a concept originally from physics. 
Table 1

Estimates of PPP Half-lives ${ }^{e}$

\begin{tabular}{|c|c|c|c|}
\hline Author(s) & & $\begin{array}{l}\text { Half-life } \\
\text { (Years) }\end{array}$ & Data \\
\hline Frankel (1990) & & 4.6 & Dollar-pound \\
\hline Abuaf and Jorion (1990) & & 3.3 & Ten industrial countries \\
\hline Manzur $(1990,1993)$ & & 5 & Seven industrial countries \\
\hline Fung and Lo (1992) & & 6.5 & Six industrial countries \\
\hline \multirow[t]{2}{*}{ Wei and Parsley (1995) } & (i) & 4.25 & European Monetary System \\
\hline & (ii) & 4.75 & Non-European Monetary System \\
\hline Frankel and Rose (1996) & & 4 & 150 countries \\
\hline Cumby (1996) & & 1 & Big Mac currencies \\
\hline \multirow[t]{2}{*}{ Lothian and Taylor (1996) } & (i) & 2.8 & Franc-pound \\
\hline & (ii) & 5.9 & Dollar-pound \\
\hline \multirow[t]{2}{*}{ Papell (1997) } & (i) & 1.9 & EC (The European Community) \\
\hline & (ii) & 2.8 & EMS \\
\hline \multirow[t]{4}{*}{ Higgins and Zakrajsek (1999) } & (i) & 5 & Europe, CPI \\
\hline & (ii) & 3 & Europe, WPI \\
\hline & (iii) & 2.5 & OECD, WPI \\
\hline & (iv) & 11.5 & Open economies, CPI \\
\hline \multirow[t]{2}{*}{ Cheung and Lai (2000) } & (i) & $(2-5)$ & Industrial countries \\
\hline & (ii) & (under 3) & Developing countries \\
\hline Median & & 4 & \\
\hline Mean & & 4.1 & \\
\hline Standard error of mean & & 2.3 & \\
\hline
\end{tabular}

Notes:

a: Where a study contains more than one estimate of half-life, we use (i), (ii), (iii) and so on to distinguish different estimates, with additional information provided in the final column of the corresponding row.

b: Where a study does not report the half-life directly, we compute it from the speed-ofadjustment estimate (on an annual basis) using $H=-\ln 2 /(\ln \beta)$ or $\left.H=-\ln 2 /\left[\ln \sum_{j=1}^{k} \beta_{j}\right)\right]$.

c: In those cases where the underlying data are not annual and the parameter estimated is, we computed the speed of adjustment per annum as, where $n$ is the number of periods per year.

d: Cheung and Lai (2000) report the range of half-life estimates for two groups of countries. To compute the mean and its standard error in the last two rows of this table, we used 3.5 and 2 years as the respective point estimates.

e: Reproduced from Lan (2003, p.25) with permission from the author and publisher. 
According to this measure, the half-life is the time taken by a given amount of PPP deviations to decay to half its magnitude (Froot and Rogoff, 1995, among others, for more discussion on PPP half-lives). A standard approach is to adopt a measure of the half-life for a general $\mathrm{AR}(1)$ process that allows asymptotic approximations around a unit root (Abuaf and Jorion, 1990, among others). Andrews (1993), and Andrews and Chen (1994) discussed half-life measures for general $\mathrm{AR}(\mathrm{p})$ processes, but do not provide a precise measure of the half-life for such processes. Another set of studies addresses this issue by constructing confidence intervals through estimating impulse response functions with various methods (Cheung and Lai, 2000).

Table 1 (reproduced from Lan, 2003, p.25) gives a summary of estimates of PPP half-lives from a set of selected studies in the literature. As can be seen, the observed half-life estimates are fairly diverse, and they range from as low as 1 year (Crumby, 1996) to 6.5 years (Fung and Lo, 1992). In addition to Crumby (1996), four other studies (namely, Abuaf and Jorion, 1990; Lothian and Taylor, 1996; Papell, 1997; and Higgins and Zakrajsek, 1999) report a half-life estimate which is 3.3 years or below. The median and mean half-lives are 4 and 4.1 years, respectively. These average figures indicate that it takes about 4 to 5 years for the PPP deviations to disappear, which is broadly consistent with the survey results reported by Froot and Rogoff (1995). However, the issue is still unresolved and far from fully understood. As Rogoff (1996) observes, it is puzzling to reconcile between the excessively high volatility of real exchange rates in the short run on the one hand, and the relatively longer half-life of PPP deviations (that is, 4 to 5 years) on the other. That is, the point estimates imply that PPP deviations are more persistent than what the conventional wisdom (sticky-price argument) would suggest (Rossi, 2005). Consequently, more work is needed to address this issue. The single currency in the euro zone provides useful test grounds for this and related issues to explore.

\section{Testing PPP with Principal Component}

We start with some notations before introducing the new test for PPP using principal component analysis (PCA). Let be a $m \times n$ matrix then $A_{. j}$ denotes the $j$ th column of $A, A_{j}$. denotes the $j$ th row of $A$, and $A^{\prime}$ denotes the transpose of $A$. Let $x$ and $y$ be two random variables then denotes the mean of $x$, $\operatorname{Var}(x)$ denotes the variance of $x$ and $\operatorname{Cov}(x, y)$ denotes the covariance between $x$ and $y$. If $x$ is a $m \times 1$ random vector then $\operatorname{Cov}(x)$ denotes the $m \times m$ variance-covariance matrix of $x$.

Now, consider the relative PPP condition,

$$
\log \left(\frac{S_{t}}{S_{t-1}}\right)=\pi_{t}^{d}-\pi_{t}^{f}
$$


where $S_{t}$ denotes the spot exchange rate in direct quote at time t, $\pi_{t}^{d}$ and $\pi_{t}^{f}$ are the inflation rate for domestic and foreign country at time $t$, respectively. The first step of testing PPP with Euro is to construct $\pi_{t}^{d}$ as a function of the inflation from the 12 Euro countries. An obvious approach is to construct a set of weights such that:

$$
\pi_{t}^{d}=\sum_{j=1}^{12} w_{j} \pi_{j t}
$$

where $w_{j}$ denotes the weight given to country $j$, and $\pi_{\mathrm{jt}}$ denotes the inflation rate for country $\mathrm{j}$ at time $t$ for $j=1, \ldots, 12$. A typical approach to determine the appropriate weights is based on the size of the economy for each country. For example, Manzur (1990), among others, used the gross domestic products as weights for the sample countries. However, this approach can be sensitive to the variables or methods used for determining the economy size, and consequently, bias the results. To avoid this problem, this paper used PCA to determine the weights. An approach based on PCA is more appropriate for this purpose for at least two reasons: (i) the dependent variable, $\pi_{t}{ }^{d}$, is unobservable, and (ii) PCA provides a set of robust weights as it is a function of inflation rates rather than the subjective measure of the economy size. ${ }^{2}$

As the application of PCA is relatively new to macroeconomics and international finance, we provide a brief outline of this procedure below.

Let $x=\left(x_{1}, x_{2}, \ldots, x_{\mathrm{m}}\right)^{\prime}$ and $y=\left(y_{1}, \ldots, y_{\mathrm{m}}\right)^{\prime}$ be two random vectors with $m$ variates, then the idea of Principal Component is to find a set of linear combinations, so that:

$$
y=w x
$$

where is a $m \times m$ matrix and:

$$
\operatorname{Cov}\left(y_{i}, y_{j}\right)=0 \forall i \neq j, \operatorname{Var}\left(y_{i}\right)>\operatorname{Var}\left(y_{j}\right) \forall i<j
$$

Note that:

$$
y-\bar{y}=w(x-\bar{x})
$$

and therefore:

$$
\operatorname{Cov}(y)=w \operatorname{Cov}(x) w^{\prime}
$$

Since $\operatorname{Cov}(y)$ is a diagonal matrix, the weight matrix, $w$, is the matrix that diagonalises $\operatorname{Cov}(x)$. Moreover, $\operatorname{Cov}(x)$ is a symmetric positive semi-definite matrix by definition, therefore $\mathrm{w}$ is the matrix consists of the eigenvectors of $\operatorname{Cov}(x)$. Specifically, $w_{\cdot}$ is $j$ th eigenvector of $\operatorname{Cov}(x)$ that corresponds to the $j$ th eigenvalue of $\operatorname{Cov}(x)$ with $w^{\prime}=w^{-1}$. This construction implies that the eigenvector associated with the largest eigenvalue is the linear combination that produces the

${ }^{2}$ For example, Germany is the largest economy among the 12 Euro-countries, but it is the most low-inflation country in the group. If the size of the economy is used as weights to calculate the pooled inflation for these 12 countries, then Germany would attract the largest weight. This would render the pooled measure to be biased and inconsistent. 
maximum variance given the random vector $x$, and the eigenvector associated with the second largest eigenvalue is the linear combination that produces the maximum remaining variance given the random vector $x . y_{i}$ is said to be the $i$ th principal component of $x$.

In the case of Euro countries, let $\pi_{t}=\left(\pi_{1 \mathrm{t}}, \ldots, \pi_{12 \mathrm{t}}\right)$ be a vector containing the inflation rates for the 12 countries, then the first principal component of $\pi_{t}$, $\pi_{t}^{\mathrm{PC} 1}$, can be used as a measure of pooled inflation, that is, a proxy for $\pi_{t}^{\mathrm{d}}$. Given the pooled inflation measure for the 12 countries, a simple regression analysis based on equation (1) can now be applied to test PPP as follows:

$$
\log \left(\frac{S_{t}}{S_{t-1}}\right)=\alpha+\beta\left(\pi_{t}^{d}-\pi_{t}^{f}\right)+\varepsilon_{t}
$$

Testing equation (1) in the form of equation (3) is equivalent to testing:

$$
\begin{aligned}
& H_{0}: \alpha=0, \quad \beta=1 \\
& H_{1}: \alpha \neq 0 \text { or } \beta \neq 1
\end{aligned}
$$

\section{Data and Empirical Analysis}

The data used in this analysis are monthly observations, obtained through the DataStream. These include the Consumer Price Index (CPI) for the 12 Euro countries, Japan, United Kingdom, and the USA, as well as the Euro/US exchange rate, Euro/Yen exchange rate and the Euro/GBP exchange rate. The sample began in December 1998 and ended in July 2007, ${ }^{3}$ with a total of 104 observations. The inflation, $\pi_{i t}$, for the USA and the 12 Euro countries were calculated as the log-difference of the corresponding CPI. All data are contained in a separate appendix, available on request.

Unless otherwise stated, the analysis in this paper was conducted using Rv2.4.1. The PCA on the inflation rates from the 12 Euro countries produced 12 eigenvalues. These are $1.714,0.684,0.279,0.203,0.144,0.075,0.044,0.040$, $0.037,0.029,0.015$ and 0.013 . Table 2 contains the factor loadings (weights) for the first principal components. As can be seen in this table, the total loading is being standardised to unity, with Greece, Ireland, Luxembourg and Spain accounting for $60 \%$ of the total loading. ${ }^{4}$ The pooled inflation rate for the 12 countries was now calculated by using equation (2) with setting equal to the set of loadings as given in Table 2 .

${ }^{3}$ Due to issues with missing data, this is the most recent and complete time series data we could obtain at the time of writing this paper.

${ }^{4}$ These estimates are likely to be unaffected by the fact that Greece was given accession to adopt Euro from 1 January, 2001. 
Table 2

Factor Loadings from the First Principal Component

Countries Austria Belgium Finland France Germany Greece Ireland Italy LuxembourgNetherlands Portugal Spain

\begin{tabular}{|l|llllllllllll}
\hline Loadings & 0.043 & 0.029 & 0.073 & 0.062 & 0.019 & 0.273 & 0.110 & 0.026 & 0.110 & 0.084 & 0.065 & 0.106
\end{tabular}

Figure 1 contains the US/Euro, GBP/Euro and Yen/Euro exchange rates (domestic currency cost of one Euro) and their corresponding growth rates for the sample period. As shown in Figure 1, the US dollar started off strong against the euro before 2002 and then it experienced a series of continuous downturns for the remainder of the sample period. This is also supported by the growth rate where the size and number of positive growth exceeded that of the negative growth. Interestingly, the dynamics of Pound/Euro and Yen/Euro resemble a very similar story to that of US/Euro. These currencies started off strong against the Euro but became weaker after 2002 .
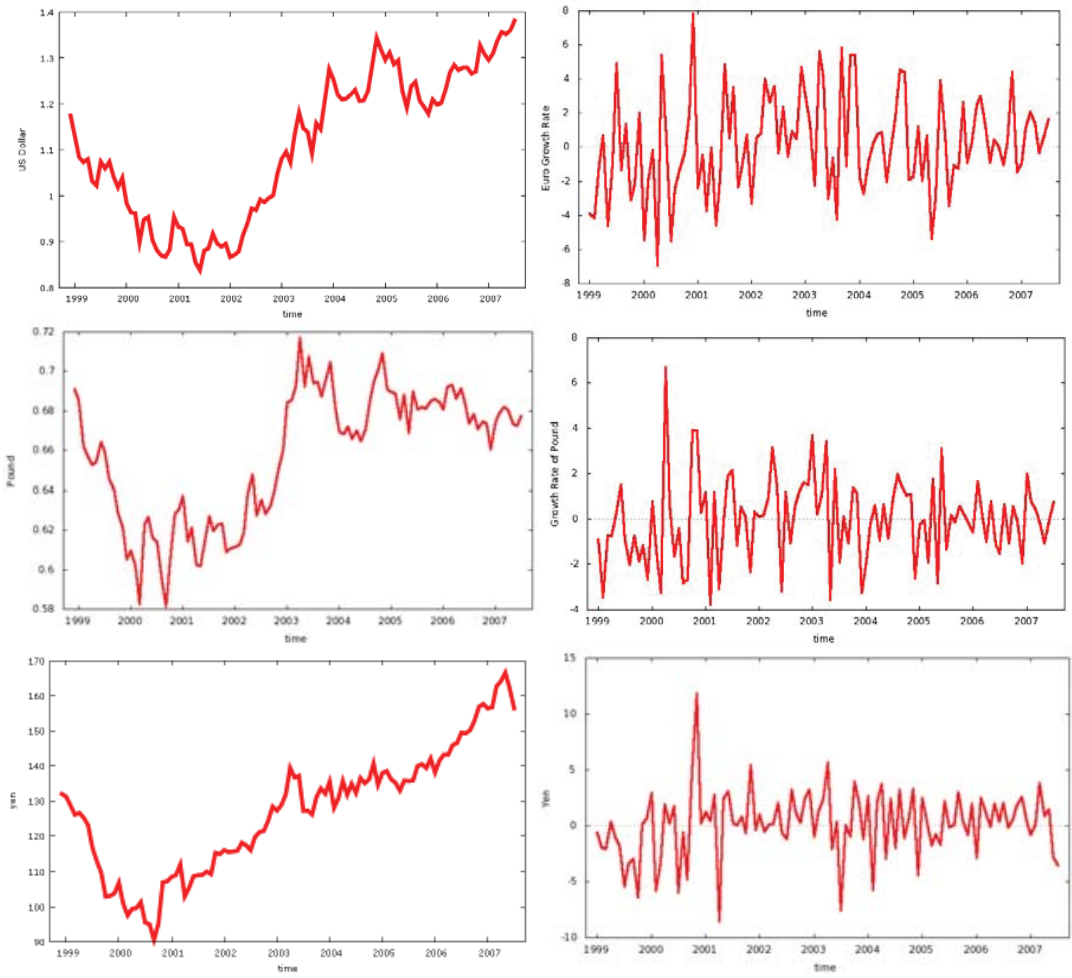

Figure 1. Exchange Rates and Their Growth Rates (December 1998-July 2007). 


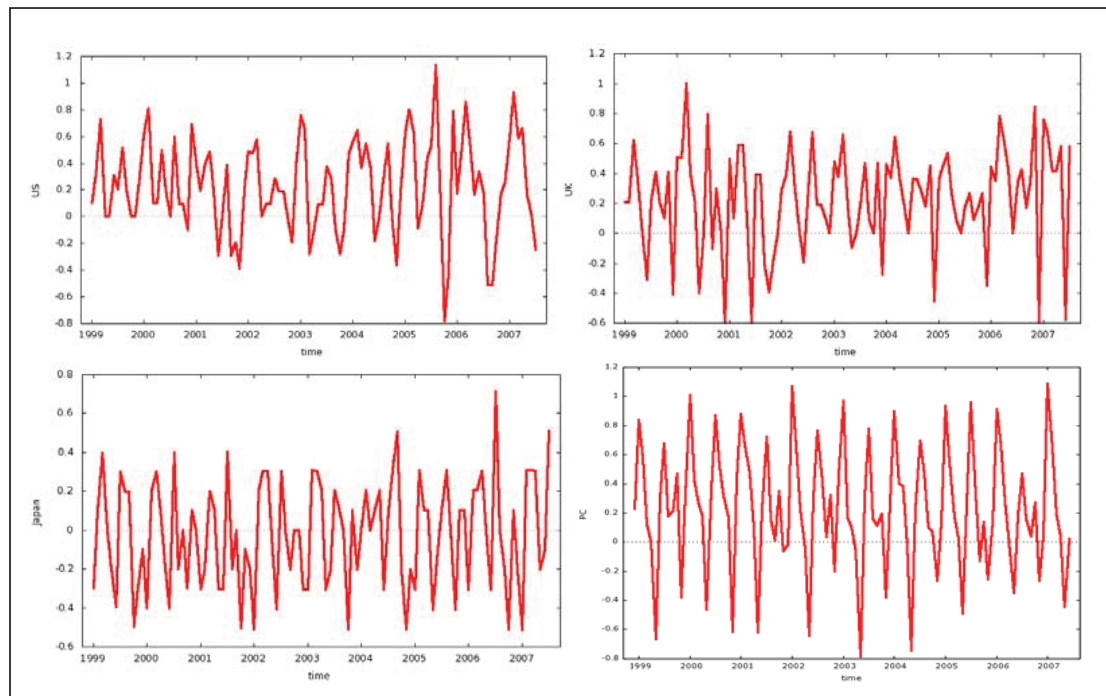

Figure 2. Inflation Rates: US, UK, Japan and Pooled Euro Countries (December 1998-Jul 2007).
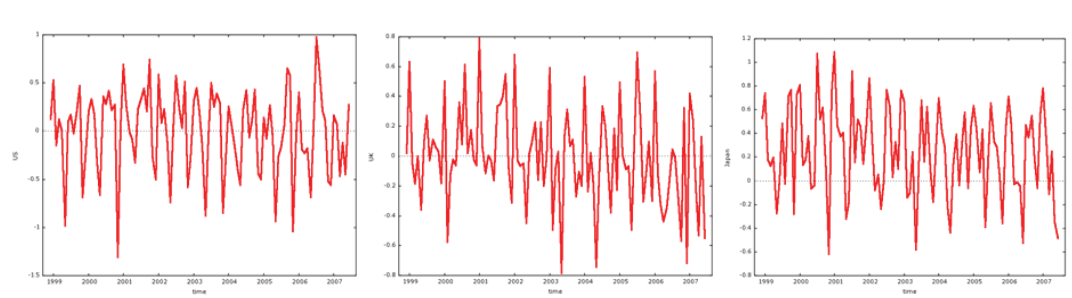

Figure 3. Inflation Differentials between Euro Pooled Inflation and the Three Countries.

Figure 2 contains the plots for the USA, UK and Japan inflation rates. This figure also includes a plot for the 'pooled' inflation (first principal component) for the 12 Euro countries. As can be seen, the USA and UK inflation rates were mostly positive in the sample period and there does not appear to be any obvious cyclical movement in the inflation rates in all four cases. A similar picture obtained in Figure 3 which plots the differentials between Euro 'pooled' inflation and that in the other three countries. (The inflation rates for the 12 Euro countries are individually given in Figure A.1 in the Appendix. Interestingly, this figure indicates that Greece, Portugal, Netherlands and Luxembourg have obvious cyclical movement in their inflation rates, whereas the cyclical patterns are not quite as obvious in the other countries. Also note that the factor loadings as reported in Table 2 are consistent with this phenomenon in Figure A.1). 
Table 3

Unit Root Tests for Exchange Rates, December 1998-Jully 2007

\begin{tabular}{lcc}
\hline & ADF Test Statistics & Asymptotic p-values \\
\hline USD/Euro (level) & -3.003 & 0.137 \\
USD/Euro (growth rate) & -9.919 & $1.165 \mathrm{e}-12$ \\
GBP/Euro (level) & -2.420 & 0.369 \\
GBP/ Euro (growth rate) & -6.363 & $1.407 \mathrm{e}-7$ \\
Yen/Euro (level) & -3.089 & 0.109 \\
Yen/Euro (growth rate) & -10.161 & $3.996 \mathrm{e}-14$ \\
\hline
\end{tabular}

Table 4

Unit Root Tests for the Regressors

\begin{tabular}{lcc}
\hline & ADF Test Statistics & Asymptotic $\mathrm{p}$-Values \\
\hline$\left(\pi_{\mathrm{t}}^{\mathrm{PC}}-\pi_{\mathrm{t}}^{\mathrm{US}}\right)$ & -9.649 & $4.391 \mathrm{e}-18$ \\
$\left(\pi_{\mathrm{t}}^{\mathrm{P} C}-\pi_{\mathrm{t}}^{\text {Japan }}\right)$ & -7.963 & $6.409 \mathrm{e}-13$ \\
$\left(\pi_{\mathrm{t}}^{\mathrm{PC}}-\pi_{\mathrm{t}}^{\mathrm{UK}}\right)$ & -6.029 & $1.022 \mathrm{e}-7$ \\
\hline
\end{tabular}

Next, we employed standard stationarity tests on the data. As can be seen in Table 3, the Augmented Dicky-Fuller (ADF) test suggests that the three exchange rates are non-stationary (in levels), while their growth rates are stationary, as expected. We also employ ADF tests on the regressors (inflation differentials) and residuals of equation (3), and the results are reported in Table 4 for the regressors and Table 5 for the residuals. The results in these two tables indicate that the ADF tests reject the null of non-stationarity in all cases. Note that employing $\mathrm{ADF}$ on the residuals in equation (3) is equivalent to testing for the presence of unit roots in real exchange rates (efficient market approach to testing PPP). Consequently, the results in Table 5 (rejection of null of nonstationarity) are encouraging for PPP.

Table 5

Unit Root Tests for the Residuals

\begin{tabular}{lcc}
\hline Residuals & ADF Test Statistics & Asymptotic p-Values \\
\hline US & -9.764 & $1.773 \mathrm{e}-13$ \\
Japan & -10.121 & $5.038 \mathrm{e}-14$ \\
UK & -6.160 & $4.883 \mathrm{e}-8$ \\
\hline
\end{tabular}


As a further check, we estimated equation (3) using ordinary least squares, and the results are presented in Table 6 for the three exchange rates. As can be seen, the results have passed the most common diagnostic tests for all three currencies. These tests include LM tests for serial correlation, heteroscedasticity and functional form, as reported in Table 6. Based on these diagnostics, the estimates of the parameters and their standard errors are now consistent, and they can be used for our hypothesis testing. As shown in Table 6 , the estimates of are significant at $10 \%$ level for US/Euro and GBP/Euro, but not significant for Yen/Euro. The coefficient estimates for $\beta$ are not significantly different from unity. Unlike the unit-root test results (in Table 5), the regression results provide a somewhat weak support for PPP in the case of US/Euro and GBP/Euro exchange rates. However, it is important to note that this seemingly weak support for PPP is fairly encouraging. The reasons for this are twofold. Firstly the data are of monthly frequency which do not favour PPP (as it is more of a long-run phenomenon, discussed in Section 2). Secondly, the sample includes introductory periods of the Euro, which are likely to be contaminated by exogenous elements. Nevertheless, the results indicate that (relative) PPP did not hold all that tightly in the beginning of the Euro introduction, but it seems reasonable to postulate that PPP might hold in the long run. In what follows, we turn to investigate this issue further.

For the long-run analysis, we employ rolling and recursive estimation procedures. Using rolling and recursive windows, estimates were obtained for the three currencies. The dynamic paths of these estimates would provide insight into the evolution of the $\beta$ estimates and their associated t-ratios (in Table 6) for all three cases. The details of the estimation methods are outlined below:

Step 1: Select the sub-sample by choosing the first $k$ observations.

Step 2: Construct the pooled measure of inflation using PCA as mentioned above with the $k$ observations

Step 3: Estimate equation (3) and save the coefficient estimates using the subsample.

Step 4: In the case of recursive windows, repeat Step 1 to Step 4 by setting $k$ $=k+1$; and in the case of rolling windows, repeat Step 2 to Step 4 by deleting the first observation of the current sub-sample and setting $k=$ $k+1$. 
Table 6

Regression Results for Relative PPP

\begin{tabular}{|c|c|c|c|c|}
\hline USD vs. Euro & Estimate & $\begin{array}{l}\text { Standard } \\
\text { Error }\end{array}$ & t-statistics & $\mathrm{p}$-values \\
\hline$\alpha$ & 0.1567 & 0.284 & 0.552 & 0.582 \\
\hline$\beta$ & 1.1001 & 0.657 & 1.676 & 0.097 \\
\hline $\mathrm{R}^{2}$ & 0.0271 & & Serial Correlation & $0.111[0.739]$ \\
\hline F-statistics & $2.808[0.097]$ & & Heteroscedasticity & $1.272[0.259]$ \\
\hline Durbin-Watson & 2.021 & & Functional Form & $0.808[0.369]$ \\
\hline \multicolumn{5}{|l|}{ Yen vs. Euro } \\
\hline$\alpha$ & 0.176 & 0.350 & 0.503 & 0.616 \\
\hline$\beta$ & -0.04615 & 0.770 & -0.060 & 0.352 \\
\hline $\mathrm{R}^{2}$ & $3.557 \mathrm{e}-05$ & & Serial Correlation & $0.041[0.840]$ \\
\hline F-statistics & $0.004[0.952]$ & & Heteroscedasticity & $0.017[0.895]$ \\
\hline Durbin-Watson & 1.999 & & Functional Form & $0.041[0.840]$ \\
\hline \multicolumn{5}{|l|}{ GBP vs. Euro } \\
\hline$\alpha$ & 0.024 & 0.179 & 0.132 & 0.896 \\
\hline$\beta$ & 1.063 & 0.549 & 1.937 & 0.056 \\
\hline $\mathrm{R}^{2}$ & 0.0358 & & Serial Correlation & $0.608[0.436]$ \\
\hline F-statistics & $3.75[0.056]$ & & Heteroscedasticity & $0.119[0.731]$ \\
\hline Durbin-Watson & 1.980 & & Functional Form & $3.841[0.309]$ \\
\hline
\end{tabular}

Note: The numbers in the square brackets are the corresponding p-values.

Figures 4 and 5 contain the dynamic paths of the $\beta$ estimates and their associated t-ratios using rolling windows, and the dynamic paths of the $\beta$ estimates and their associated t-ratio using recursive windows, for all three exchange rates, respectively.
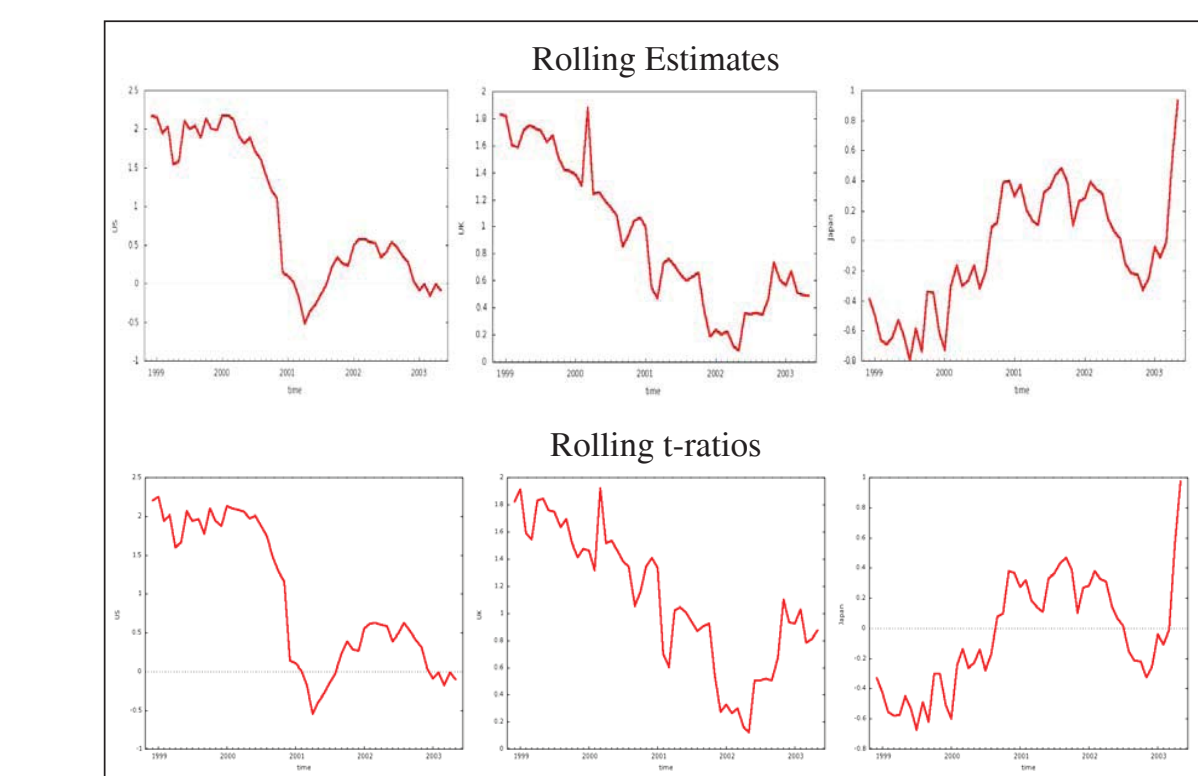

Rolling t-ratios
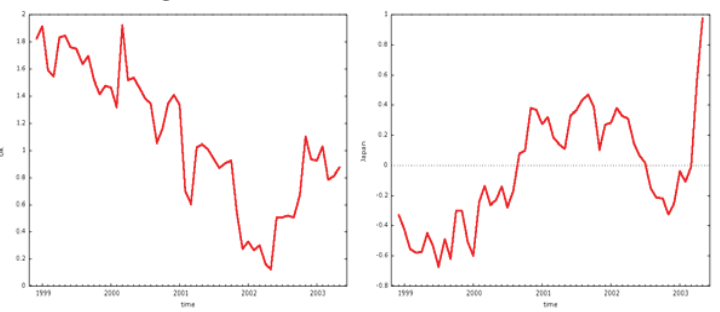

Figure 4. Dynamic Paths of and their t-ratios using Rolling Windows. 
Both rolling and recursive windows start from the first observation of our sample. As can be seen, for both USD/Euro and GBP/Euro, the dynamic paths of the $\beta$ estimates exhibited a downward trend toward 1 . This tends to be consistent with our results reported above, that is, relative PPP did not hold in the early stage of the Euro introduction, but it seems to be valid over time for US and UK. However, the dynamic path of the $\beta$ estimates is very unique in the case of Yen/Euro. As shown in Figure 4, the rolling estimates of $\beta$ suggests that relative PPP did not hold for much of the sample period, which is also supported by the dynamic path of the recursive estimates as shown in Figure 5. However, the sharp and dramatic increase in the $\beta$ estimates toward the end of the sample seems to suggest the tendency toward relative PPP. These results tend to suggest that (i) relative PPP did not hold in the initial period of Euro introduction for US, UK and Japan; and (ii) there is a tendency towards relative PPP for the three currencies over time.

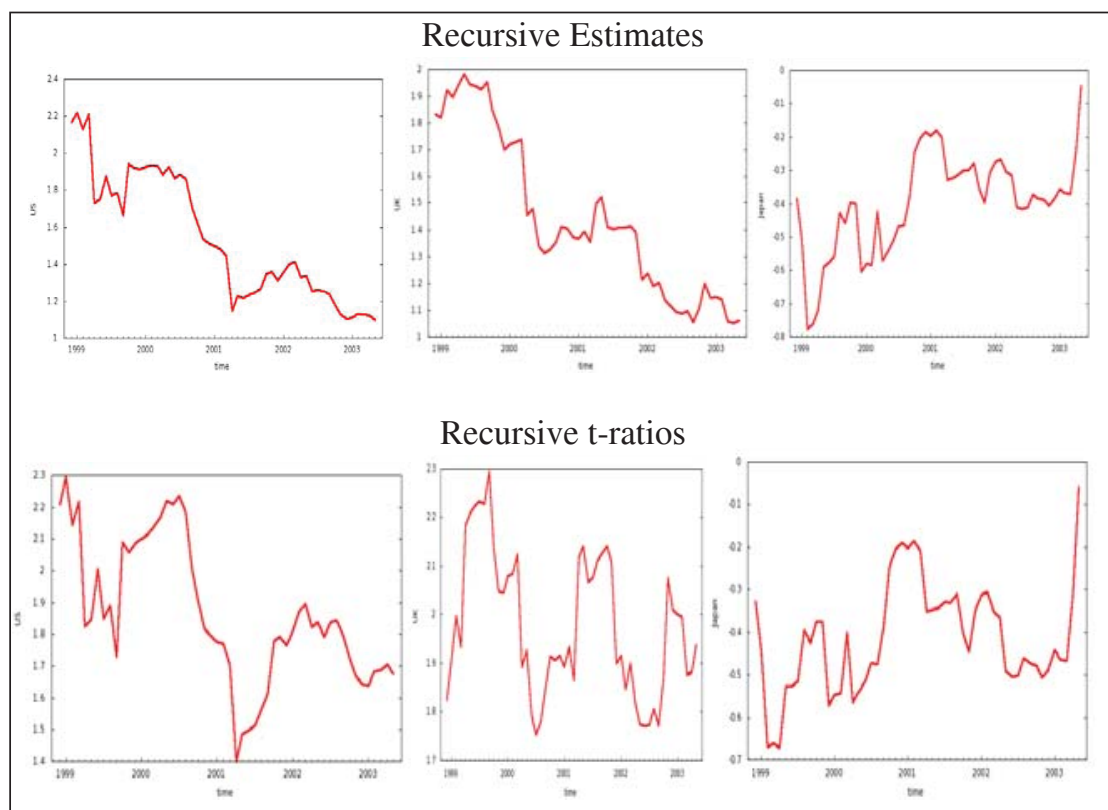

Figure 5. Dynamic Paths of $\hat{\beta}$ and their t-ratios using Recursive Windows.

Based on the results above, it is now straightforward to estimate the rate of convergence in figures. This is achieved by analysing the dynamic of the recursive $\beta$ estimates as provided above. A possible model to consider is:

$$
\hat{\beta}_{t}=A_{0} \exp \left(\gamma t+u_{t}\right) \quad u_{t} \sim \operatorname{iid}\left(0, \sigma_{u}\right)
$$


where $\hat{\beta}_{t}$ denotes the $\beta$ estimate at the $\mathrm{t}^{\text {th }}$ recursive window and thus $\gamma$ represent the rate of decay which can be interpreted as the rate of convergence in this case. To see this, differentiate equation (5) with respect to $t$ and rearranging gives:

$$
\gamma=\frac{d \hat{\beta}_{t}}{d t} \frac{1}{\hat{\beta}_{t}}
$$

which implies that $\gamma$ measures the percentage changes in $\hat{\beta}_{t}$ due to a small change in $t$. The parameter in equation (5) can be estimated using ordinary least squares by taking the logarithmic transformation, which yields:

$$
\log \left(\hat{\beta}_{t}\right)=\log \left(A_{0}\right)+\gamma t+u_{t}
$$

Table 7 contains the $\gamma$ estimates for US/Euro, GBP/Euro and Yen/Euro. As can be seen, the estimates are highly significant in all three cases. Surprisingly, although the $\beta$ estimates exhibited seemingly different dynamic over time, the rate of convergence is very similar in absolute terms. This result is significant, as it indicates that the tendency towards PPP underlying each currency is very similar in the long run, even though the PPP deviations are persistent in the short run.

\section{Table 7}

Estimates of the Rate of Convergence to PPP

\begin{tabular}{lllc}
\hline & US/Euro & GBP/Euro & Yen/Euro \\
\hline$\hat{\gamma}$ & -0.013 & -0.012 & 0.015 \\
$t(\hat{\gamma})$ & -17.12 & -19.57 & 4.452 \\
\hline
\end{tabular}

The necessary condition for PPP to hold is that $\beta=1$, therefore given the estimates of $\log \left(A_{0}\right)$ and $\gamma$, it is possible to calculate the expected time for each currency to converge toward PPP. This can be done by substituting in equation (6) and solving for $t$. Table 8 contains the results for the three exchange rates. Note that as the observations are monthly, is measured in terms of months and hence, dividing by 12 will give the estimated year of convergence toward longrun PPP for each currency.

Table 8

Estimates of Time for Convergence to PPP

\begin{tabular}{cccc}
\hline & US/Euro & GBP/Euro & Yen/Euro \\
\hline$t$ (in months) & 59.627 & 54.247 & 38.770 \\
Year & 4.969 & 4.687 & 3.230 \\
\hline
\end{tabular}


As shown in Table 8, the length of the long run for PPP for both US/ Euro and GBP/Euro is around five years, consistent with several other results discussed in Section 2. Interestingly, while the earlier results were not supportive of PPP for Yen/Euro (as shown in Table 6), the adjustment towards PPP for this exchange rate is faster, just a little over three years. It is, however, to be noted that that Yen/Euro rates had the highest volatility in terms of the dynamic of in Figures 4 and 5 (also see Figure 1).

\section{Does PPP Outperform the Random Walk Model?}

A major business implication of PPP is that it provides a simple prediction model for exchange rates. If an exchange rate (in level) is over- or undervalued relative to that implied by PPP, it is straightforward to form an expectation about its future movements. How accurate are the predictions based on PPP? In what follows, we provide a brief analysis of this issue.

Based on PPP, Equation (3) can be used to forecast exchange rates given previous exchange rates and the rates of inflation. The pooled inflation rate for the 12 Euro countries were calculated based on the first principle component of their inflation rates using the first 50 observations and the remaining 54 observations will be used to compare the out-of-sample forecasts. The performance of this model was compared with the unit root model (no-change extrapolation) and the synthetic Euro series provided by European Central Bank against the currencies of the USA, UK and Japan. The three conventional measures of forecast errors, namely, Mean Square Errors (MSE), Mean Absolute Errors (MAE) and Mean Absolute Percentage Errors (MAPE), are used for comparison purposes. These measures are defined as follows:

$$
\begin{aligned}
& \text { Mean Squared Error (MSE) }=\quad h^{-1} \sum_{t=1}^{h}\left(y_{t}-\hat{y}_{t}\right)^{2} \\
& \text { Mean Absolute Error (MAE) }=\quad h^{-1} \sum_{t=1}^{h}\left|y_{t}-\hat{y}_{t}\right| \\
& \text { Mean Absolute Percentage Error (MAPE) }=\quad h^{-1} \sum_{t=1}^{h}\left|y_{t}-\hat{y}_{t}\right| / y_{t}
\end{aligned}
$$

where $y_{\mathrm{t}}$ and denote the observed exchange rate and the predicted exchange rate at time $t$, respectively and $h$ is the forecast horizon which equals to 54 in this case. The MSE, MAE and MAPE for the three currencies under the three models are presented in Table 9. As can be seen, the forecast performance of the PPP model is very similar to those of the other two models. For US/Euro, PPP clearly outperforms the synthetic Euros of ECB, and performs at least as well as the random walk model. The results for Yen/Euro and GBP/Euro are marginally mixed, but qualitatively (and statistically) very similar. Overall, the result is highly encouraging for PPP. 
Table 9

Forecast Performance: PPP, Random Walk and Synthetic Euro

\begin{tabular}{cccc}
\hline US/Euro & Unit Root & PPP Euro using PCA & Synthetic Euro \\
\hline MSE & 0.001 & 0.001 & 0.007 \\
MAE & 0.025 & 0.026 & 0.070 \\
MAPE & 0.023 & 0.023 & 0.063 \\
\hline Yen/Euro & & & \\
\hline MSE & $6.587 \mathrm{e}-8$ & $6.746 \mathrm{e}-8$ & $1.035 \mathrm{e}-9$ \\
MAE & $1.768 \mathrm{e}-4$ & $1.844 \mathrm{e}-4$ & $2.283 \mathrm{e}-5$ \\
MAPE & 0.021 & 0.022 & 0.003 \\
\hline GBP/Euro & & & $9.356 \mathrm{e}-9$ \\
MSE & $8.187 \mathrm{e}-4$ & $7.899 \mathrm{e}-4$ & $7.355 \mathrm{e}-5$ \\
MAE & 0.022 & 0.022 & $4.738 \mathrm{e}-5$ \\
MAPE & 0.014 & 0.014 & \\
\hline
\end{tabular}

\section{Conclusions}

This paper has provided a new test of PPP and its relevance for the Euro. We introduce the method of principal component analysis (PCA) to construct a 'pooled' measure of inflation among the 12 Euro countries. As the overall inflation of the 12 Euro countries is not observable, we maintain that a PCA on the inflation of 12 Euro countries provides a consistent measure of 'pooled inflation' for the Euro zone. The results indicate that the high-inflation countries in the Euro zone (such as Greece and Ireland) receive larger weights in the pool. This measure of inflation is used to test the PPP condition for the Euro against the currencies of USA, UK and Japan. The results provide a somewhat weak support for PPP in the case of US/Euro and GBP/Euro exchange rates, and a rejection of PPP for Yen/Euro. However, this seemingly weak support for PPP is fairly encouraging, for at least two reasons. Firstly, the data are of monthly frequency which do not favour PPP (as it is more of a long-run phenomenon, discussed in Section 2). Secondly, the sample includes introductory periods of the euro, which are likely to be contaminated by exogenous elements.

The test results were then used to measure the speed of adjustment of the deviations from PPP using rolling and recursive regressions procedures. The results tend to suggest that (i) relative PPP did not hold in the initial (introductory) periods of Euro for the three currencies under this study; and (ii) there is a tendency towards relative PPP for all three currencies over time. The PPP half-lives are found to be about five years for US/Euro and GBP/Euro exchange rates, but just a little over three years for Yen/Euro. The accuracy of the PPP-based euro exchange rates is compared with those given by simple forecasting rules such as no-change extrapolation, and the synthetic euro series provided by the European Central Bank. The results indicated that the forecast 
performance of the PPP model is very similar to those of the other two models. For US/Euro, PPP clearly outperforms the synthetic Euros of ECB, and performs at least as well as the random walk model. The results for Yen/Euro and GBP/ Euro were slightly mixed, but qualitatively (and statistically) very similar. This result is highly encouraging for PPP.

The empirical results of this paper are expected to provoke further work on this issue at least in two directions. The first is the issue of appropriate statistical procedures to employ for estimating the PPP half-lives (Rossi, 2005). However, the half-life estimate for Yen/Euro (compared to those for US/Euro and GBP/ Euro) in this paper indicates that appropriate estimation procedures may be less of an issue in this case. Consequently, further research will concentrate more towards the second direction: the role of economic fundamentals in explaining the persistence of PPP deviations. Note that in estimating the 'pooled' inflation in this paper, the differences in inflation in 12 European countries (having one currency) are allowed for, but we have not explained the differences. Thus, it may be possible in future research to examine these cross-country inflation differences within the euro-zone more closely in explaining PPP deviations.

Author information: Submitting author, Assoc Professor Meher Manzur, Curting Business School, GPO Box U1987, Perth, WA 6845, Australia. E-mail; meher.manzur@cbs.curtin.edu.au. The authors are thankful to Ariful Hoque and Muammer Wali for excellent research assistance. Financial support from Curtin Business School is gratefully acknowledged.

\section{Appendix}
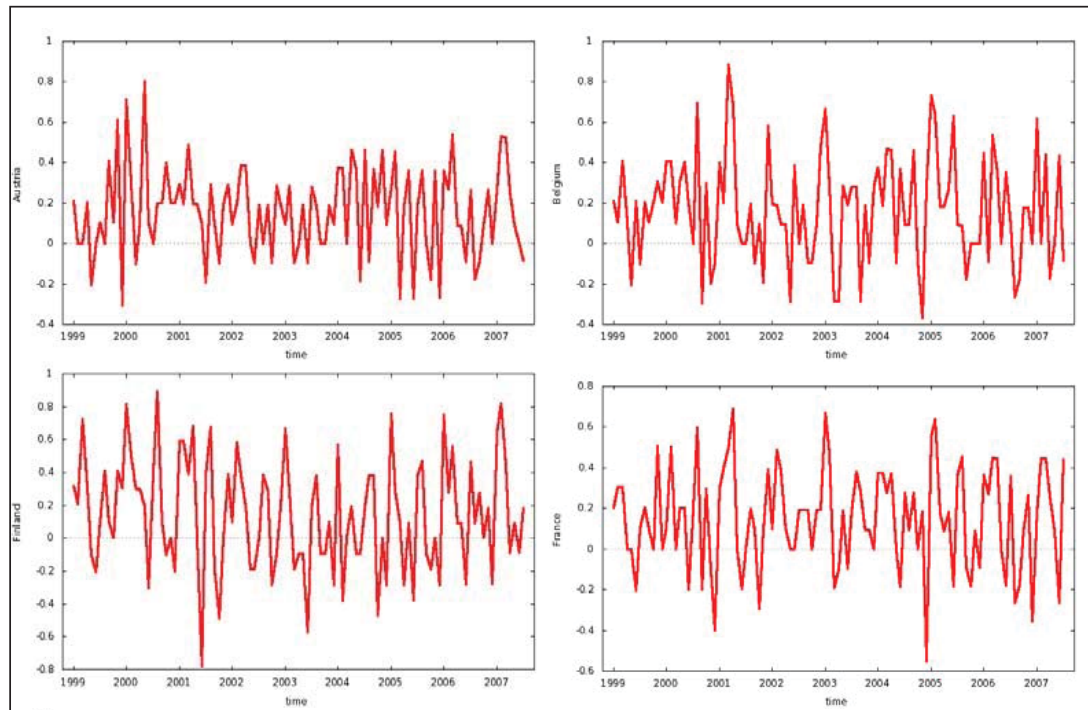

Figure A1. Inflation Rates: 12 Euro Countries (December 1998-July 2007). 


\section{Appendix}

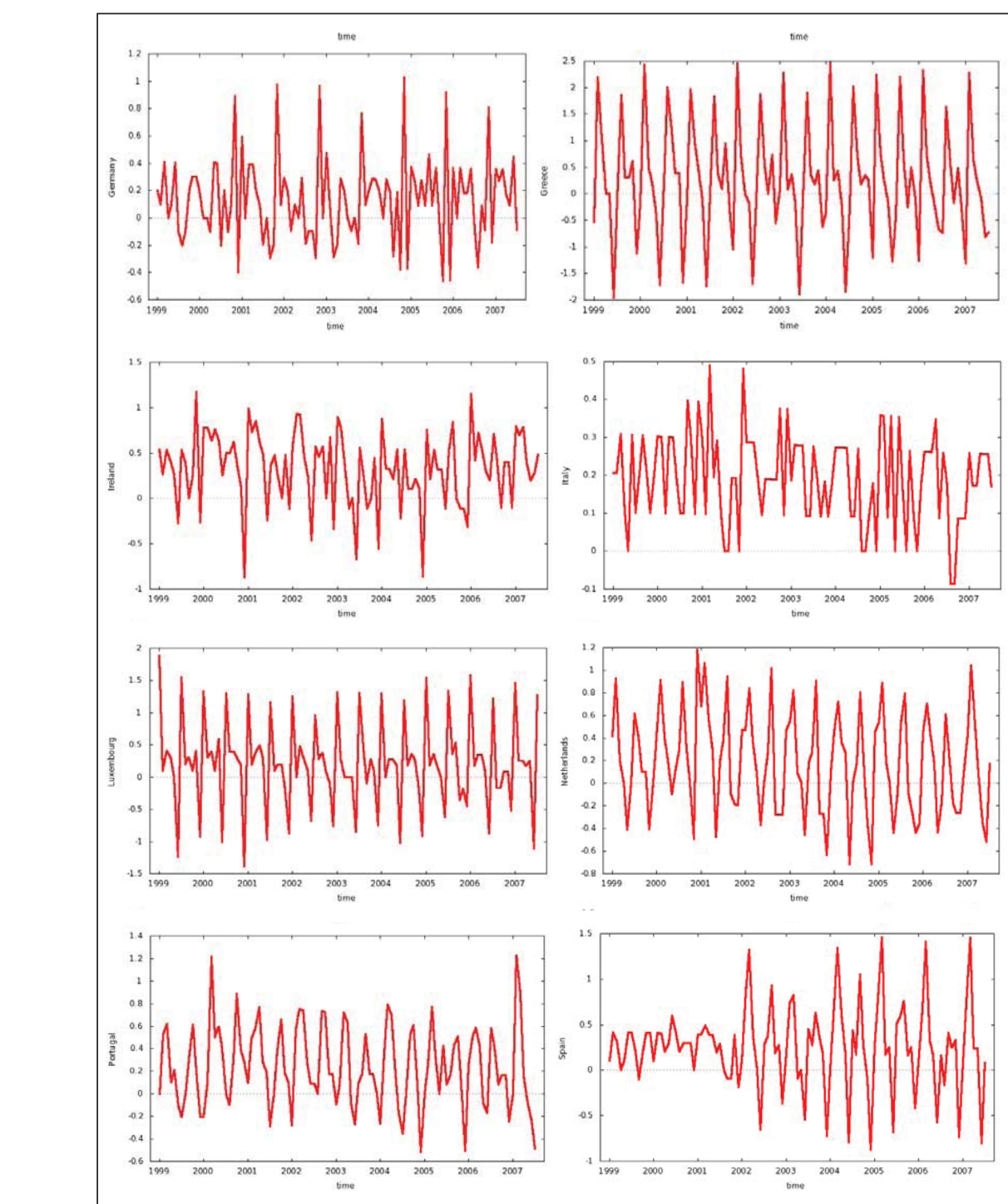

Figure A1. Inflation Rates: 12 Euro Countries (December 1998-July 2007).

\section{References}

Abuaf, N. and Jorion, P. (1990). Purchasing power parity in the long run. Journal of Finance, 45,157-174.

Andrews, D. (1993). Exactly median-unbiased estimation of autoregressive/unit root models. Econometrica, 61, 139-166. 
Andrews, D. and Chen, H-Y. (1994). Approximately median-unbiased estimation of autoregressive models. Journal of Business and Economic Statistics, 12, 187-204.

Bahmani-Oskooee, M., and Nasir ABM. (2005). Productivity bias hypothesis and the purchasing power parity: A review article. Journal of Economic Surveys, 19, 671-696.

Balassa, B. (1964). The purchasing power parity doctrine: A reappraisal. Journal of Political Economy, 72, 584-596.

Cheung, Y-K. and Lai, K. (2000). On purchasing power parity puzzle. Journal of International Economics, 52, 321-330.

Crumby, R. (1996). Forecasting exchange rates and relative prices with the hamburger standard: Is what you want what you get with McParity? NBER Research Paper 5675. Massachusetts: National Bureau of Economic Research.

Fung, H. and Lo, W. (1992). Deviations from purchasing power parity. The Financial Review, 27, 553-570.

Devereux, M., and Engel, C. (2002). Exchange rate pass-through, exchange rate volatility, and exchange rate disconnect. Journal of Monetary Economics, 49, 913-940.

Dornbusch, R. (1976). Expectations and Exchange Rate Dynamics. Journal of Political Economy, 84, 1161-1176.

Frankel, J. and Rose, A. (1996). A panel project on purchasing power parity: mean reversion and between countries. Journal of International Economics, 40, 209-224.

Froot, K. and Rogoff, K. (1995). Perspectives on PPP and long run real exchange rates. In G. Grossman and K. Rogoff (Eds), Handbook of international economics (pp. 1647-1688). Amsterdam: North-Holland Press.

Higgins, M. and Zakrajsek, (1999). Purchasing power parity: Three stakes through the heart of the unit root null. Staff Paper No. 80. Federal Reserve Bank of New York.

Koedijk, K., Ben, T. and Mathijs, A. (2004). Purchasing power parity and the euro area. Journal of International Money and Finance, 23, 1081-1107.

Lothian, J. and Taylor, M. (1996). Rela exchange rate behaviour: The recent float from the perspective of the past two centuries. Journal of Political Economy, 104, 488-510.

Lan, Y. (2003). The Explosion of Purchasing Power Parity. In Manzur M. (Ed.), Exchange rates interest rates and commodity prices (2nd ed.)(pp. 1-8). Cheltenham, Edward Elgar.

Manzur, M. (1990). An international comparison of prices and excahange rates: A new test of purchasing power parity. Journal of International Money and Finance, 9, 75-91.

Manzur, M. (2003). Exchange rates interest rates and commodity prices: An introduction. In Manzur M. (Ed.), Exchange rates interest rates and commodity prices (pp. 1-8). Edward Elgar, 